\title{
DESEMPENHO VEGETATIVO DE CLONES DE SERINGUEIRA NA REGIÃO DE SÃO JOSÉ DO RIO PRETO - SP
}

\section{ARTIGO ORIGINAL}

COSTA, Maria Vitória Cecchetti Gottardi ${ }^{1}$

BERTOLIN, Danila Comelis ${ }^{2}$

SIMONATO, Adriano Luis ${ }^{3}$

NASCIMENTO, Douglas Prescilio do 4

PASSARIN, Luiz Antônio ${ }^{5}$

COSTA JÚNIOR, Jarbas Gabriel ${ }^{6}$

GONÇALVES, Paulo de Souza ${ }^{7}$

COSTA, Maria Vitória Cecchetti Gottardi. Et al. Desempenho vegetativo de clones de seringueira na Região de São José do Rio Preto - SP. Revista Científica Multidisciplinar Núcleo do Conhecimento. Ano 05, Ed. 10, Vol. 22, pp. 120-132.

1 Pós Doutorado. Doutorado em Agronomia. Mestrado em Agronomia. Aperfeiçoamento em Programa Seringueira. Graduação em Engenharia Agronômica.

2 Doutorado em Agronomia (Produção Vegetal). Mestrado em Agronomia (Produção Vegetal). Graduação em Engenharia Agronômica.

${ }^{3}$ Doutorado em Agronomia (Produção Vegetal). Mestrado em Matemática. Graduação em Bacharelado em Matemática.

${ }^{4}$ Graduação em Biologia e Tecnólogo em Agronegócio.

5 Técnico em Agropecuária.

${ }^{6}$ Pós Graduação e Graduação: Tecnólogo em Processos Gerencias.

7 Doutorado em Genética e Melhoramento de Plantas. Mestrado em Melhoramento Florestal. Graduação em Agronomia. 
Outubro

de

2020.

ISSN:

2448-0959,

Link

de acesso: https://www.nucleodoconhecimento.com.br/agronomia/clones-de-seringueira

\section{RESUMO}

O Estado de São Paulo é a região do Brasil de maior importância no cultivo da seringueira [Hevea brasiliensis (Willd. exAdr. de Juss.) Muell. Arg.] e é na região noroeste a qual vem se destacando, devido ao clima quente que favorece o desenvolvimento e a produção desta cultura. Com a crescente demanda por borracha natural e a intensificação de novos plantios na região de São Jose do Rio Preto - SP, noroeste paulista, a utilização de clones adaptados e altamente produtivos são de suma importância para o sucesso da exploração do seringal. O presente trabalho teve por objetivo avaliar o desempenho de sete anos de desenvolvimento vegetativo de dezoito clones de seringueira. A área experimental foi instalada na Fazenda de Ensino, Pesquisa e Extensão da Fatec Rio Preto, em São José do Rio Preto - SP, sob o delineamento de blocos inteiramente casualizados com três repetições. Foram avaliados os seguintes caracteres vegetativos: altura da planta, número de lançamentos foliares, perímetro do caule e incremento anual do caule. Dados das mensurações do período vegetativo mostraram que os clones PB 311, PB 312, RRIM 911, PB 314 e RRIM 600 apresentaram os melhores desempenhos e aos sete anos atingiram um percentual de $46,0 \%, 43,5 \%, 43,3 \%, 41,8 \%$ e $41,7 \%$ de árvores aptas para sangria, respectivamente. Os clones PB 326; PB 346, PB 350, IAC 328 e IAC 330 foram excluídos, durante as avaliações devido ao fato da maioria das plantas não terem sobrevivido, fato este que pode estar relacionado a períodos de pouca incidência de chuvas ocorridos na região.

Palavras-chave: Heveicultura, seleção de clones, desempenho de clones, Hevea brasiliensis.

\section{INTRODUÇÃO}

Originária da região amazônica, a seringueira [Hevea brasiliensis (Willd. exAdr. de Juss.) Muell. Arg.], vem sendo domesticada pelo homem em função do látex produzido 
que é a maior fonte de borracha natural do mundo, matéria prima utilizada na fabricação de pneumáticos e em grande número de manufaturados (GONÇALVES et al., 2002). Desde a introdução das primeiras sementes de seringueira no Estado de São Paulo em 1916 e o plantio comercial desta cultura em 1950, a heveicultura vem solidificando suas bases no Noroeste Paulista (CATI, 2010). A região noroeste do Estado de São Paulo, onde o clima quente favorece o desenvolvimento e a produção da seringueira, responde por mais de $65 \%$ da área plantada no Brasil e São José do Rio Preto representa 27\% deste total (OLIVEIRA e GONÇALVES, 2019).

No Brasil, o cultivo da seringueira está presente em doze estados: São Paulo, Bahia, Mato Grosso, Minas Gerais, Goiás, Espírito Santo, Pará, Tocantins, Mato Grosso do Sul, Paraná, Amazonas e Acre. Este setor emprega uma pessoa por quatro hectares, sendo responsável por 80 mil postos de trabalho no país com mais de 25 mil famílias vivendo do produto da seringueira (FAMATO, 2016). A borracha natural é uma importante commodity agrícola, considerada produto estratégico para a economia global (HEVEA BRASIL, 2016).

De acordo com a Apabor (2018) a sustentabilidade ambiental e reponsabilidade social são grandes destaques do produto nacional pelo fato de que $90 \%$ da borracha no mundo é produzida em agricultura familiar em países com zonas rurais com baixo índice educacional, social e pouca preservação ambiental. No Brasil, é produzida de forma profissional, apresentando para o mundo uma borracha natural, livre de trabalho infantil, sem desmatamento e exploração de mão de obra.

Segundo Martins et al. (2013), o plantio de novas áreas, principalmente na região noroeste paulista, vem crescendo de modo significativo graças ao desenvolvimento de pesquisa e tecnologia, e do potencial de geração de renda e emprego. Entretanto, a maioria das informações disponíveis sobre o comportamento dos clones recomendados para o plantio é extrapolada de outras regiões, sendo extremamente importante a avaliação do comportamento destes clones em cada região.

A necessidade da recomendação de clones adaptáveis a diferentes regiões é de fundamental importância para o sucesso do cultivo da seringueira. Clones produtivos 
em determinadas regiões, podem não serem em outras áreas da mesma região, devido a diferentes características edafoclimáticas. Entretanto à medida que a heveicultura vai se expandindo, aumentam as preocupações referentes ao comportamento dos clones plantados, necessitando de pesquisas que possa envolver recomendação de diferentes clones para as diferentes regiões. Desse modo, a avaliação de clones para obtenção dos mais produtivos e adaptados para diferentes regiões de cultivo de seringueira se faz necessária (GONÇALVES, 1986; GONÇALVES et al., 1993; GONÇALVES et al., 1998; GONÇALVES, 2002; PEREIRA, 2006; CATI, 2010).

A utilização de clones altamente produtivos e que reúnam um maior número de caracteres desejados é de suma importância para o sucesso da exploração do seringal (GONÇALVES et al., 1993).

Diante do exposto, este trabalho teve por objetivo avaliar o desempenho vegetativo de clones de seringueira para futura seleção dos que apresentarem melhor desenvolvimento e produção para sua recomendação na região de São José do Rio Preto - SP.

\section{METERIAL E MÉTODOS}

O experimento foi instalado no campo em julho de 2013, na Fazenda de Ensino, Pesquisa e Extensão da Fatec Rio Preto, São Jose do Rio Preto - SP, em solo argissolo vermelho-amarelo, eutrófico típico a moderado, textura arenosa média. Predomina nessa área o clima tropical subquente e úmido com temperatura média anual de $25^{\circ} \mathrm{C}$. A estação quente, com temperaturas médias acima de $26,4^{\circ} \mathrm{C}$, compreende os meses de outubro a março, apresentando as maiores médias térmicas entre os meses de janeiro a fevereiro. A estação menos quente, com médias superiores a $21^{\circ} \mathrm{C}$ compreende os meses de abril a setembro e as medias térmicas menores abrangem os meses de junho e julho. A umidade relativa do ar anual é cerca de $68 \%$ e a estação chuvosa ocorre nos meses de outubro a março, com $85 \%$ da precipitação total anual e a estação seca, abrange os meses de abril a setembro, com apenas $15 \%$ da precipitação total anual (REZENDE e RANGA, 2005). 
Em campo o ensaio obedeceu ao delineamento experimental de blocos inteiramente casualizado, com dezoito tratamentos, três repetições e oito plantas por parcela, com 2 testemunhas, no espaçamento de $8 \mathrm{~m}$ entre linhas de plantio e 2,5 m entre plantas. Foram utilizados os clones: RRIM 713, RRIM 729, RRIM 908, RRIM 911, RRIM 913, PB 233, PB311, PB 312, PB 314, PB 326, PB 346, PB 350, IAC 328, IAC 330, IAC 56, PC 140 e como testemunha, RRIM 600 e GT1.

Durante o período do desenvolvimento vegetativo dos clones, efetuaram-se mensurações anuais de perímetro do caule a $0,5 \mathrm{~m}$ acima do calo de enxertia no primeiro ano e a 1,20 m acima do calo de enxertia começando do segundo ano; incremento anual de crescimento do caule: obtido pela diferença das avaliações do perímetro do caule posterior com as anteriores; altura da planta e número de lançamentos foliares, realizadas em três mensurações, a primeira aos seis meses após o plantio, a segunda após um ano e a terceira após dois anos de plantio.

$\mathrm{Na}$ execução do experimento, empregaram-se todas as práticas culturais convencionais ao cultivo da seringueira (CATI, 2010).

\section{RESULTADOS E DISCUSSÃO}

Dos 18 clones utilizados, cinco: PB 326; PB 346, PB 350, IAC 328 e IAC 330, foram retirados durante o desenvolvimento do experimento devido ao fato de quase todas as plantas não terem sobrevivido. Este fato pode estar relacionado as mudanças climáticas observadas na região de São José do Rio Preto - SP, que desde outubro de 2013, quando o experimento foi instalado no campo, ocorreram períodos de seca prolongada, pouca incidência de chuva, em alguns anos com registro de seca histórica na região. Como o presente trabalho teve por objetivo avaliar o desempenho dos clones de seringueira para futura seleção dos que apresentarem alto potencial de produção, vigor e caracteres secundários satisfatórios para sua recomendação, estes clones deveriam ser utilizados com cautela em locais com as mesmas condições enfrentadas no trabalho. Segundo Macedo et al. (1999), o estabelecimento de espécies florestais de rápido crescimento no campo é avaliada nos primeiros períodos após o plantio, por meio da sua capacidade de sobrevivência, pois é sob estas 
condições de campo que geralmente as mudas de diferentes espécies/clones florestais diferem em suas expressões fenotípicas de vigor, demonstrando sua capacidade de adaptação às condições locais.

$\mathrm{Na}$ Tabela 1 encontram-se as avaliações referentes as médias da altura total de plantas e número de lançamentos foliares. $\mathrm{Na}$ terceira mensuração não houve diferença significativa em ambas avaliações. Para altura total de plantas os clones RRIM 600 e PB 311, apresentaram maior desenvolvimento, enquanto os clones RRIM 908 e RRIM 713 os menores desenvolvimentos. Com relação ao número de lançamentos foliares os clones IAC 56 e PB 312 apresentaram maior média e os clones RRIM 713 e RRIM 911 menor média. De acordo com Macedo et al. (2002), certos clones podem apresentar um crescimento inicial lento e desenvolver-se rapidamente em fases posteriores ao estabelecimento, o que sugere mudança no comportamento com o passar dos anos passando ao grupo de melhor desempenho adquirindo uma melhor interação genótipo $\mathrm{x}$ ambiente onde os clones mais adaptados sobressaem em relação aos demais.

Tabela 1. Valores médios da altura total de plantas $(\mathrm{m})$ e número de lançamento foliares referente as três mensurações realizadas dos treze clones de seringueira estabelecidos no experimento.

\begin{tabular}{|l|l|l|l|l|l|l|}
\hline Clone & \multicolumn{2}{|l}{ Altura total de plantas $(\mathrm{m})$} & \multicolumn{3}{l|}{ Número de lançamentos foliares } \\
& $\mathbf{2 0 1 4}$ & $\mathbf{2 0 1 4}$ & $\mathbf{2 0 1 5}$ & $\mathbf{2 0 1 4}$ & $\mathbf{2 0 1 4}$ & $\mathbf{2 0 1 5}$ \\
& jan & julh & julh & jan & julh & julh \\
& & & & & & \\
\hline RRIM 713 & $0.61 \mathrm{ab}$ & $1.07 \mathrm{ab}$ & $1.56 \mathrm{a}$ & $2.49 \mathrm{a}$ & $3.00 \mathrm{abcd}$ & $2.23 \mathrm{a}$ \\
\hline RRIM 729 & $0.51 \mathrm{ab}$ & $0.98 \mathrm{bcd}$ & $1.58 \mathrm{a}$ & $1.97 \mathrm{a}$ & $2.93 \mathrm{abcd}$ & $2.50 \mathrm{a}$ \\
\hline RRIM 908 & $0.55 \mathrm{ab}$ & $0.92 \mathrm{bcd}$ & $1.52 \mathrm{a}$ & $2.12 \mathrm{a}$ & $2.80 \mathrm{abcd}$ & $2.82 \mathrm{a}$ \\
\hline RRIM 911 & $0.59 \mathrm{ab}$ & $1.06 \mathrm{~b}$ & $1.72 \mathrm{a}$ & $2.36 \mathrm{a}$ & $3.04 \mathrm{abcd}$ & $2.24 \mathrm{a}$ \\
\hline RRIM 913 & $0.54 \mathrm{ab}$ & $0.89 \mathrm{bcd}$ & $1.69 \mathrm{a}$ & $1.98 \mathrm{a}$ & $2.62 \mathrm{abcd}$ & $2.37 \mathrm{a}$ \\
\hline PB 233 & $0.41 \mathrm{ab}$ & $0.70 \mathrm{bcd}$ & $1.72 \mathrm{a}$ & $1.87 \mathrm{a}$ & $2.78 \mathrm{abcd}$ & $2.75 \mathrm{a}$ \\
\hline
\end{tabular}




\begin{tabular}{|l|l|l|l|l|l|l|}
\hline PB 311 & $0.71 \mathrm{a}$ & $1.56 \mathrm{a}$ & $1.97 \mathrm{a}$ & $2.37 \mathrm{a}$ & $3.57 \mathrm{a}$ & $2.83 \mathrm{a}$ \\
\hline PB 312 & $0.65 \mathrm{ab}$ & $1.14 \mathrm{ab}$ & $1.79 \mathrm{a}$ & $2.37 \mathrm{a}$ & $3.23 \mathrm{abc}$ & $2.92 \mathrm{a}$ \\
\hline PB 314 & $0.54 \mathrm{ab}$ & $1.02 \mathrm{bc}$ & $1.62 \mathrm{a}$ & $1.98 \mathrm{a}$ & $2.57 \mathrm{abcd}$ & $2.89 \mathrm{a}$ \\
\hline IAC 56 & $0.38 \mathrm{~b}$ & $0.49 \mathrm{~d}$ & $1.78 \mathrm{a}$ & $1.95 \mathrm{a}$ & $2.10 \mathrm{~cd}$ & $3.00 \mathrm{a}$ \\
\hline PC 140 & $0.45 \mathrm{ab}$ & $0.69 \mathrm{bcd}$ & $1.61 \mathrm{a}$ & $2.02 \mathrm{a}$ & $2.37 \mathrm{bcd}$ & $2.67 \mathrm{a}$ \\
\hline GT 1 & $0.55 \mathrm{ab}$ & $0.92 \mathrm{bcd}$ & $1.64 \mathrm{a}$ & $2.62 \mathrm{a}$ & $3.40 \mathrm{ab}$ & $2.76 \mathrm{a}$ \\
\hline RRIM 600 & $0.64 \mathrm{ab}$ & $1.04 \mathrm{bc}$ & $1.98 \mathrm{a}$ & $2.16 \mathrm{a}$ & $2.86 \mathrm{abcd}$ & $2.84 \mathrm{a}$ \\
\hline
\end{tabular}

Obs: médias seguidas de pelo menos uma letra em comum não diferem entre si pelo teste de Tukey a nível de $5 \%$ de probabilidade.

Fonte: Elaborado pelos autores, 2020

As avaliações de desenvolvimento vegetativo das plantas no campo quanto ao perímetro do caule estão representadas na Tabela 2. Pode-se observar que não houve diferença significativa entre os clones nas duas últimas mensurações realizada (anos de 2019 e 2020).

Tabela 2. Valores médios do perímetro do caule $(\mathrm{cm})$, referente aos sete anos de desenvolvimento vegetativo dos treze clones de seringueira estabelecidos no experimento.

\begin{tabular}{|c|c|c|c|c|c|c|c|}
\hline Clone & $\begin{array}{l}2014 \\
\left(1^{\circ} \text { ano }\right)\end{array}$ & $\begin{array}{l}2015 \\
\left(2^{\circ}\right. \\
\text { ano })\end{array}$ & $\begin{array}{l}2016 \\
\left(3^{\circ}\right. \\
\text { ano) }\end{array}$ & $\begin{array}{l}2017 \\
\left(4^{\circ} \text { ano }\right)\end{array}$ & $\begin{array}{l}2018 \\
\text { (5ªno) }\end{array}$ & $\begin{array}{l}2019 \\
\left(6^{\circ} \text { ano }\right)\end{array}$ & $\begin{array}{l}2020 \\
\left(7^{\circ} \text { ano }\right)\end{array}$ \\
\hline $\begin{array}{l}\text { RRIM } \\
713\end{array}$ & $0,90 \mathrm{ab}$ & $5,07 a b$ & $7,03 \mathrm{~b}$ & $15,33 \mathrm{~b}$ & $23,60 \mathrm{bcd}$ & $31,88 a$ & $38,66 a$ \\
\hline $\begin{array}{l}\text { RRIM } \\
729\end{array}$ & $0,79 a b$ & $4,47 a b$ & $7,83 \mathrm{ab}$ & $15,67 \mathrm{~b}$ & $22,45 \mathrm{bcd}$ & $31,61 a$ & $38,36 a$ \\
\hline $\begin{array}{l}\text { RRIM } \\
908\end{array}$ & $0,84 a b$ & $4,43 a b$ & 7,47 b & $14,67 \mathrm{~b}$ & $20,71 \mathrm{~d}$ & $29,73 a$ & $37,02 a$ \\
\hline
\end{tabular}




\begin{tabular}{|c|c|c|c|c|c|c|c|}
\hline $\begin{array}{l}\text { RRIM } \\
911\end{array}$ & $0,92 a b$ & $6,03 \mathrm{ab}$ & $9,23 a b$ & $17,33 \mathrm{~b}$ & $29,05 \mathrm{a}$ & $32,52 a$ & $43,33 a$ \\
\hline $\begin{array}{l}\text { RRIM } \\
913\end{array}$ & $\begin{array}{l}0,73 \\
a b c\end{array}$ & $5,32 a b$ & $8,30 a b$ & $16,50 \mathrm{~b}$ & $23,45 \mathrm{bcd}$ & $30,67 a$ & $36,10 a$ \\
\hline PB 233 & $\begin{array}{l}0,72 \\
a b c\end{array}$ & $7,11 \mathrm{a}$ & $11,08 \mathrm{a}$ & $17,00 \mathrm{~b}$ & $23,22 \mathrm{bcd}$ & $28,33 a$ & $36,86 a$ \\
\hline PB 311 & $1,15 a$ & $5,72 a b$ & $10,83 a$ & $22,67 \mathrm{a}$ & $28,96 \mathrm{a}$ & $37,59 a$ & $46,03 a$ \\
\hline PB 312 & $0,97 a b$ & $4,56 \mathrm{ab}$ & $7,83 \mathrm{ab}$ & $\begin{array}{l}18,33 \\
a b\end{array}$ & $\begin{array}{l}24,56 \\
\text { abcd }\end{array}$ & $33,35 a$ & $43,50 a$ \\
\hline PB 314 & $0,88 a b$ & $3,61 \mathrm{~b}$ & $7,92 \mathrm{ab}$ & $16,17 b$ & $\begin{array}{l}25,73 \\
\text { abcd }\end{array}$ & $34,80 a$ & $41,80 a$ \\
\hline IAC 56 & $0,63 \mathrm{bc}$ & $5,00 a b$ & $7,83 \mathrm{ab}$ & $15,83 \mathrm{~b}$ & $21,61 \mathrm{~cd}$ & $31,53 a$ & $35,91 a$ \\
\hline PC 140 & $\begin{array}{l}0,72 \\
a b c\end{array}$ & $3,67 \mathrm{~b}$ & 7,02 b & $\begin{array}{l}18,67 \\
a b\end{array}$ & $25,98 a b c$ & $35,40 a$ & $39,66 a$ \\
\hline GT 1 & $0,84 \mathrm{ab}$ & $4,54 a b$ & $7,53 \mathrm{~b}$ & $16,83 \mathrm{~b}$ & $21,49 \mathrm{~cd}$ & $31,80 a$ & $37,75 a$ \\
\hline $\begin{array}{l}\text { RRIM } \\
600\end{array}$ & $\begin{array}{l}0,72 \\
a b c\end{array}$ & $5,92 a b$ & $9,30 a b$ & $\begin{array}{l}18,50 \\
a b\end{array}$ & $27,00 a b$ & $33,04 a$ & $41,68 a$ \\
\hline
\end{tabular}

Obs: médias seguidas de pelo menos uma letra em comum não difere entre si pelo teste de Tukey a nível de $5 \%$ de probabilidade.

Fonte: Elaborado pelos autores, 2020

Os clones com melhor desenvolvimento foram: PB 311, PB 312, RRIM 911, PB 314, seguido da testemunha RRIM 600, com 46,03; 43,50;43,33; 41,80 e 41,68 cm, respectivamente. Estes clones se destacaram dos demais com as maiores médias do perímetro do caule, o que sugere uma melhor adaptação as condições locais de plantio. Lavorenti et al. (1990) em estudo sobre a relação entre diferentes caracteres de plantas jovens de seringueira, destacaram o perímetro do caule como responsável por 36\% da variação da produção, um dos caracteres que juntamente com espessura de casca, número de anéis de vasos laticíferos, distância entre anéis, diâmetro dos vasos laticíferos e índice de tamponamento determinam a maior produção de látex. $O$ 
caráter mais importante que permite um retorno mais rápido do investimento do heveicultor é o vigor, medido através do perímetro do caule, que determinar a precocidade do clone (ALEM et al., 2015).

A menor média do perímetro do caule foi observada nos clones PB 233, RRIM 913 e IAC 56, este último apresentando baixo desenvolvimento desde 2017.

Na Figura 1, podemos visualizar o comportamento dos clones estudados, nos sete anos de avaliação, em relação à média do perímetro do caule.

Figura 1. Comparativo dos valores médios do perímetro do caule $(\mathrm{cm})$ nos anos de 2014, 2015, 2016, 2017, 2018, 2019 e 2020, dos treze clones de seringueira estabelecidos no experimento.

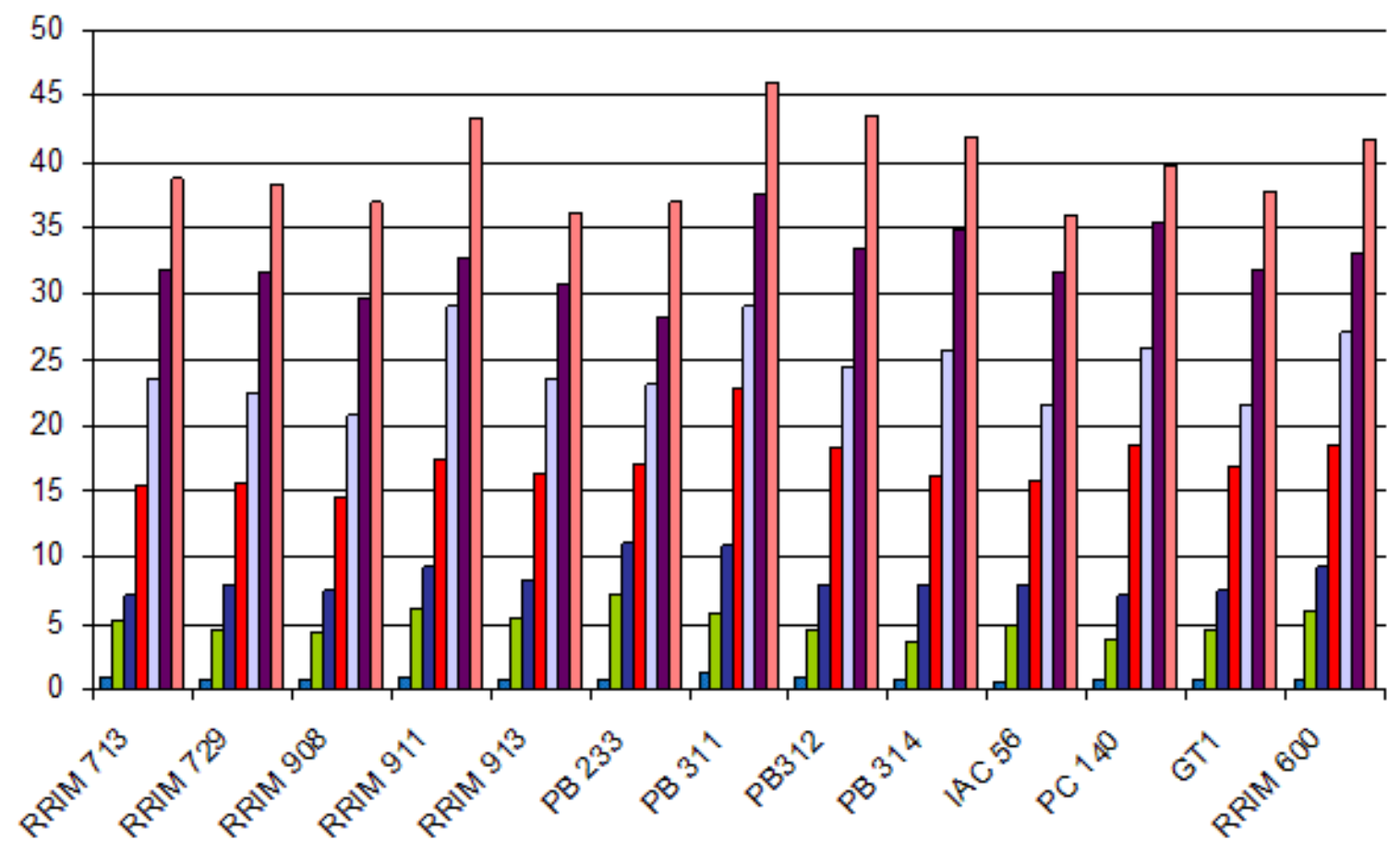

ロ $2014 \square 2015 \square 2016 \square 2017 \square 2018$ ロ $2019 \square 2020$

Fonte: Elaborado pelos autores, 2020

Com relação ao incremento anual de crescimento do caule, pode-se observar uma redução dos incrementos nos anos de 2015 - 2016 e 2017 - 2018. Na sétima 
mensuração (2019 - 2020), apenas os clones RRIM 911, PB 312, PB 233 e RRIM 600 apresentaram aumento no incremento do caule em comparação a anterior (Tabela 3). Esta redução dos incrementos anuais de crescimento do caule pode estar relacionada as mudanças climáticas observadas na região de São José do Rio Preto - SP, pois desde a implantação do experimento foram registrados períodos de pouca incidência de chuva. Gonçalves et al. (1993) em seu trabalho com análise de desempenho de clones de seringueira na região de São José do Rio Preto, também observaram redução dos incrementos anuais do caule, durante o período de desenvolvimento vegetativo, devido deficiência hídrica, corroborando com os dados encontrados no presente trabalho.

Segundo Ortolani et al. (1996) vários elementos agroclimáticos tais como déficit hídrico, temperatura e pluviosidade que afetam vários componentes do crescimento e produção contribuem com uma grande soma de variabilidades no comportamento dos clones. Clones tidos como produtivos em algumas regiões do Brasil podem comportarse diferentemente em outras áreas da mesma região, principalmente aquelas sujeitas a diferentes características edafoclimáticas.

Tabela 3. Valores médios do incremento anual de crescimento do caule $(\mathrm{cm})$, referente aos sete anos de desenvolvimento vegetativo dos treze clones em estudo.

\begin{tabular}{|c|c|c|c|c|c|c|}
\hline \multirow[t]{3}{*}{ Clone } & \multicolumn{6}{|l|}{ Ano } \\
\hline & 2014 & 2015 & 2016 & 2017 & 2018 & 2019 \\
\hline & 2015 & 2016 & 2017 & 2018 & 2019 & 2020 \\
\hline RRIM 713 & 4,17 & 1,69 & 8.30 & 8,27 & 8,28 & 6,78 \\
\hline RRIM 729 & 3,68 & 3,36 & 7.84 & 6,78 & 9,16 & 6,75 \\
\hline RRIM 908 & 3,58 & 3,04 & 7.20 & 6,04 & 9,02 & 7,29 \\
\hline RRIM 911 & 5,11 & 3,20 & 8,10 & 11,72 & 3,47 & 10,81 \\
\hline RRIM 913 & 4,59 & 2,98 & 8,20 & 6,95 & 7,22 & 5,43 \\
\hline PB 233 & 6,39 & 3,97 & 5,92 & 6,22 & 5,11 & 8,53 \\
\hline PB 311 & 4,57 & 5,11 & 11.84 & 6,29 & 8,63 & 8,44 \\
\hline PB 312 & 3,59 & 3,27 & 10,50 & 6,23 & 8,79 & 10,15 \\
\hline
\end{tabular}




\begin{tabular}{|l|l|l|l|l|l|l|}
\hline PB 314 & 2,73 & 4,31 & 8,25 & 9,56 & 9,07 & 7,00 \\
\hline IAC 56 & 4,37 & 2,83 & 8,00 & 5,78 & 9,92 & 4,38 \\
\hline PC 140 & 2,95 & 3,35 & 11,65 & 7,31 & 9,42 & 4,26 \\
\hline GT 1 & 3,70 & 2,99 & 9,30 & 4,66 & 10,31 & 5,95 \\
\hline RRIM 600 & 5,20 & 3,38 & 9,20 & 8,50 & 6,04 & 8,64 \\
\hline
\end{tabular}

Fonte: Elaborado pelos autores, 2020

$\mathrm{Na}$ Tabela 4 estão representadas a porcentagem de plantas, por clone, aptas para extração do látex, ou seja, apresentaram a 1,20 m de altura do calo de enxertia um perímetro do caule igual ou superior a $45 \mathrm{~cm}$ (CATI, 2010). Segundo Gonçalves et al. (2001) e Oliveira e Gonçalves (2019), a seringueira apresenta uma fase juvenil (período vegetativo) entre seis a oito anos após o plantio, momento em que se inicia a extração do látex, dependendo do nível de manejo empregado. O mesmo foi observado no presente experimento aos sete anos de idade, no final do período vegetativo e início do período produtivo.

Tabela 4. Porcentagem de plantas aptas, por clone, para início da extração do látex.

\begin{tabular}{|l|l|}
\hline Clone & Planta apta para extração do látex \\
\hline RRIM 713 & 25 \\
\hline RRIM 729 & 22 \\
\hline RRIM 908 & 12,5 \\
\hline RRIM 911 & 43,3 \\
\hline RRIM 913 & 36,1 \\
\hline PB 233 & 36,7 \\
\hline PB 311 & 46,0 \\
\hline PB 312 & 43,5 \\
\hline PB 314 & 41,8 \\
\hline IAC 56 & 35,9 \\
\hline PC 140 & 39,6 \\
\hline
\end{tabular}




\section{\begin{tabular}{l|l} 
GT 1 & 37,7
\end{tabular} \\ RRIM $600 \quad 41,7$}

Fonte: Elaborado pelos autores, 2020

Os clones PB 311, PB 312, RRIM 911, PB 314 e RRIM 600 alcançaram no sétimo ano 46,0; 43,5; 43,3; 41,8 e 41,7\%, respectivamente, a porcentagem mínima recomendada de $40 \%$ de plantas aptas para sangria, índice aceitável para início da exploração de um seringal de acordo com a Cati (2010).

O clone RRIM 600 tomado como referência, por ser o mais plantado no Brasil, segundo Pereira (1997), e utilizado como testemunha no presente trabalho, apresentou desenvolvimento intermediário, fato este observado por Pereira et al. (2001), em trabalho realizado sobre desempenho de clones de seringueira sob diferentes sistemas de sangria. Já o clone GT1, um dos clones mais universais, também utilizado como testemunha, não apresentou bom desempenho, fato este também observado em trabalho realizado por Goncalves et al. (1993) sobre desempenho de clones de seringueira na região de São Jose do Rio Preto.

De maneira geral os clones PB 311, PB 312, RRIM 911, PB 314 e RRIM 600 se destacaram dos demais nas avalições realizadas no período vegetativo. Segundo Gonçalves et al. (2002) a introdução de clones de seringueira em uma determinada região, bom como o seu desempenho são fundamentais para o fornecimento de dados científicos, visando recomendações precisas para o desenvolvimento desejado da cultura.

\section{CONCLUSÕES}

As conclusões do presente trabalho se baseiam apenas no desempenho da fase vegetativa de clones de seringueira na região de São Jose do Rio Preto.

Os clones PB 311, PB 312, RRIM 911, PB 314 e RRIM 600 apresentaram o melhor desempenho no decorrer do período de avaliação da fase vegetativa, alcançando mais rapidamente o período de sangria, permitindo a exploração e o retorno 
econômico precocemente. O clone GT 1, utilizado como testemunha, mostrou baixo desempenho vegetativo.

Os clones PB 326; PB 346, PB 350, IAC 328 e IAC 330, não apresentaram bom desempenho nas variáveis analisadas no presente trabalho.

\section{AGRADECIMENTOS}

Os autores agradecem ao Engenheiro Agrônomo Dr. Erivaldo José Scaloppi Júnior, Pesquisador da Agência Paulista de Tecnologia para Agronegócios (APTA Votuporanga, SP) na obtenção das borbulhas; ao viveiro de mudas Citrosol, na produção dos clones de seringueira; a Usina de Latex e Borracha Natural Colitex, na instalação do experimento e a MEPEL, na doação de tanque para irrigação das plantas no campo.

\section{REFERÊNCIAS}

ALEM, H.M.; GOUVÊA, L.R.L.; SILVA, G.A.P.; OLIVEIRA, A.L.B.; GONÇALVES, P.S. Avaliação de clones de seringueira para a região noroeste do estado de São Paulo. Rev. Ceres, Viçosa, v. 62, n.5, p. 430-437, 2015.

\section{APABOR, 2018. O Brasil é o maior produtor de borracha natural da América} Latina. Disponível em: http://www.remade.com.br/noticias/14934/brasil-e-o-maiorprodutor-de-borracha-natural-da-america-latina Acesso em: 20/02/2020.

CATI. A cultura da seringueira para o Estado de São Paulo, coordenado por Eliana Cristine Piffer Gonçalves. Campinas, CATI (Manual Técnico, 72), 2010, 163p.

FAMATO. Dia do Seringueiro, 2016. Disponível em: http://sistemafamato.org.br/portal/famato/noticia_completa.php?codNoticia=236543\#: :text=No\%20Brasil\%2C\%20a\%20seringueira\%20\%C3\%A9,mil\%20hectares\%20de $\% 20 \%$ C3\%A1rea\%20plantada. Acesso em 02/04/2020. 
GONÇALVES, P de S. Melhoramento genético da seringueira. In: Simpósio sobre a cultura da seringueira no Estado de São Paulo, Fundação Cargill, 1986, p. 95 - 123.

GONÇALVES, P. de S.; CARDOSO, M.; MENTE, E. M.; MARTINS, A. L. M.; GOTTARDI, M. V. C.; ORTOLANI, A. A. Desempenho preliminar de clones de seringueira na região de São José do Rio Preto, planalto do Estado de São Paulo. Bragantia, Campinas, v. 52, n. 2, p. 19-30, 1993.

GONÇALVES, P. S., BORTOLETO, N., SANTOS, W. R., ORTOLANI, A. A., GOTTARDI, M. V. C., MARTINS, A. L. M. Avaliação Genética de Progênies em Meiosirmãos de Seringueira em Diferentes Regiões do Estado de São Paulo. Pesquisa Agropecuária Brasileira. v.33, p.1085 - 1095, 1998.

GONÇALVES, P. S., BATAGLIA, O.C.; ORTOLANI, A. A., FONSECA, F da S. Manual de heveicultura para o Estado de São Paulo. Campinas, Instituto Agronômico. 2001, 78p. (Instituto Agronômico. Boletim Técnico 189).

GONÇALVES, P. S. Uma história de sucesso: a seringueira no Estado de São Paulo, O Agronômico, Campinas, v.54, n.1, p.6-10, 2002.

GONÇALVES, P. S; MARTINS, A.L.M; FURTADO, E.L.; SAMBUGARO, R.; OTTATI, E.L.; ORTOLANI, A.A.; GODOY JUNIOR, G. Desempenho de clones de seringueira da série IAC 300 na região do planalto de São Paulo. Pesquisa Agropecuária Brasileira., v.37, n.2, p.131 - 138, 2002.

HEVEA BRASIL: Seringueiros contribuem para a geração de emprego e renda, 2016. Disponível em: http://www.heveabrasil.com/ Acesso em 07/04/2020.

LAVORENTI, C. GONÇALVES, P.S.; CARDOSO, M.; BOAVENTURA, M.M.; MARTINS, A.L.M. Relação entre diferentes caracteres de plantas jovens de seringueira. Bragantia. Campinas. v.49, n.1, p.93-103, 1990.

MACEDO, R.L.G.; BOTELHO, S.A.; SCOLFORD, J.R. Considerações preliminares sobre o estabelecimento de Tectona grandis L.f. (Teca), introduzida na região 
noroeste do Estado de Minas Gerais. In: SIMPOSIO SOBRE ECOSSISTEMAS FLORESTAIS, 5, 1999, Curitiba. Anais... Rio de Janeiro: Biosfera, 1999.

MACEDO, R.L.G.; OLIVEIRA, T.K.; VENTURIN, N.; GOMES, J.E. Introdução de clones de seringueira no noroeste do estado de Minas Gerais. CERNE, v.8, n.1, p.124133, 2002.

MARTINS, A.L.M.; LUCA, C.A.; GONÇALVES E.C.P.; BRITO, P.F. Produção de mudas de seringueira em bancadas e substrato. CATI, 2013.

OLIVEIRA, M.D.M.; GONÇALVES, E.C.P. Custo de Produção e Rentabilidade da Cultura da Seringueira: safra 2018/19. 2019 Disponível em: http://www.iea.sp.gov.br/out/TerTexto.php?codTexto=14567. Acesso em 18/09/2019.

ORTOLANI, A.A.; SENTELHAS, P.C.; CAMARGO, M.B.P.; PEZZOPANE, J.E.M.; GONÇALVES, P.S. 1996. Agrometeorological models to estimate annual and seasonal production of latex in rubber. Revista Brasileira de Agrometeorologia, v.4, n 1, p. 147-150, 1996.

PEREIRA, A.V. Avaliação preliminar do desempenho de clones de seringueira (Hevea spp) no estado de Goiás e no Distrito Federal. Tese (Doutorado) Universidade Federal de Lavras, Lavras, p.98. 1997.

PEREIRA, A.V. PEREIRA, E.B.C.; BENESI, J.F.C. Desempenho de clones de seringueira sob diferentes sistemas de sangria. Boletim de pesquisa e desenvolvimento/Embrapa Cerrados, 2001. 19p.

PEREIRA, A.V. Novos clones de seringueira. In: V Ciclo de Palestras Sobre a Heveicultura Paulista, 2006, p126-144.

REZENDE, A.A., RANGA, N.T. Lianas da estação ecológica do Noroeste Paulista, São José do Rio Preto/Mirassol, SP, Brasil. Acta Botânica Brasileira, v.19, p.273279, 2005.

Enviado: Agosto, 2020. 
Aprovado: Outubro, 2020. 